\title{
Towards integrating water prediction and control technology*
}

\author{
P.J. van Overloop, R.R. Negenborn, D. Schwanenberg, and \\ B. De Schutter
}

If you want to cite this report, please use the following reference instead:

\begin{abstract}
P.J. van Overloop, R.R. Negenborn, D. Schwanenberg, and B. De Schutter, "Towards integrating water prediction and control technology," Proceedings of the 2011 IEEE International Conference on Networking, Sensing and Control, Delft, The Netherlands, pp. 80-85, Apr. 2011.
\end{abstract}

Delft Center for Systems and Control

Delft University of Technology

Mekelweg 2, 2628 CD Delft

The Netherlands

phone: +31-15-278.24.73 (secretary)

URL: https: //www.dcsc.tudelft.nl 


\title{
Towards Integrating Water Prediction and Control Technology
}

\author{
P.J. van Overloop, R.R. Negenborn, D. Schwanenberg, B. De Schutter, Member, IEEE
}

\begin{abstract}
In most countries, especially in deltas, there is a long tradition in the management of water resource systems, in particular related to structural measures such as the construction of dikes and riverine/coastal hydraulic structures. We discuss how this infrastructure can be supported and managed in order to serve as non-structural measures. Therefore, we present a review about technology for the prediction and control of water resources. This covers techniques for flow and water quality forecasting including modeling and data assimilation as well as its combination with predictive controllers for managing hydraulic structures. These techniques are discussed both from a conceptual and technical perspective. Furthermore, we give an overview about ongoing and future work in this field, which is aimed at integrating the techniques from both the water prediction and the water control community.
\end{abstract}

\section{INTRODUCTION}

For multiple reasons, such as the access to international trade, the possibility to transport goods over inland waters, and having irrigation water available all year round, people tend to live close to water ways. Water ways in delta areas on the one hand receive their flows from precipitation of upstream areas and on the other can receive additional water from high sea levels. Each of these influences is variable in time and may result either in extremely high or extremely low water levels, which consequently can lead to undesired inundation and droughts, respectively. Inundation is undesirable due to loss of crops, damaging of houses and residential areas, and in the extreme cases human casualties. Droughts are undesirable, since they cause damage to potential crops, non-navigable water ways, insufficient cooling water for power plants, high water temperatures causing toxic algae growth and fish mortality, and potential danger for securing drinking water.

In order to deal with threats of these potential damages, people implement measures. This is an ongoing process,

Manuscript received November 1, 2010. This research was supported by the VENI project "Intelligent multi-agent control for flexible coordination of transport hubs" (project 11210) of the Dutch Technology Foundation STW, a subdivision of the Netherlands Organization for Scientific Research (NWO), the BSIK project "Next Generation Infrastructures (NGI)", the Delft Research Center Next Generation Infrastructures, and the European STREP project "Hierarchical and distributed model predictive control (HD-MPC)", contract number INFSO-ICT-223854.

P.J. van Overloop is with the Department of Water Management, Delft University of Technology, Delft, The Netherlands (e-mail: p.j.a.t.m.vanoverloop@tudelft.nl).

R.R. Negenborn is with the Department of Marine and Transport Technology, Delft University of Technology, Delft, The Netherlands (e-mail: r.r.negenborn@tudelft.nl).

D. Schwanenberg is with Deltares, Delft, The Netherlands (e-mail: dirk.schwanenberg@deltares.nl).

B. De Schutter is with the Delft Center for Systems and Control, Delft University of Technology, Delft, The Netherlands (e-mail: b.deschutter@tudelft.nl). mainly because the demands that society imposes on safety, wealth, and well-being continue to increase. The measures that are being implemented can be of a structural or of a nonstructural nature. On the one hand, non-structural measures are measures that can be taken to adverse threatening situations in real-time, taking into account the actual situation. On the other hand, structural measures are measures that do not have this flexibility and that do not take into account the actual situation. E.g., in order to avoid casualties due to inundations, as a structural measure, the dikes protecting the land from the water can be raised or, as a non-structural measure, an evacuation plan can be developed, which aims at moving out the people of the threatened area as quick as possible.

Structural measures are usually seen as safer to most people. However, this feeling of safety comes at a high price, since structural measures are usually very costly. In fact, guaranteeing $100 \%$ security against inundation and droughts using only structural measures is simply unaffordable for society. Moreover, structural measures are not flexible and are therefore only prepared and optimized for dealing with the contingencies and situations envisioned at design time. Non-structural measures do not have these drawbacks.

To illustrate the potential of non-structural measures, consider as an example a spillway used for filling an emergency inundation area to relieve the pressure on the river dikes due to high river flows. Figure 1 illustrates the non-optimal filling of a system with a structural spillway. If the spillway is designed as a structural measure without any control, it would be designed to function autonomously. It would be a fixed weir with a design width and a design height that are based on a certain design high water wave passing through the water way. For precisely this design wave the structural spillway can top off the peak. However, for any wave with a different shape, peak height, or duration the structural spillway will either cause a not completely filled inundation area or a fully inundated area before the actual peak of the wave arrives. When the spillway measure is designed as a non-structural measure, it can be implemented as an undershot gate that can be opened or closed at the right time, depending on the actual situation at hand. Due to this added flexibility, the inundation area can be used in an optimal way and the peak of the wave can be lowered as much as possible. The operation of the gate, however, requires knowledge on the future system behavior, i.e., a quantitative prediction of the approaching flood event.

Presently consensus exists that both types of measures, structural and non-structural, need to be considered when upgrading water systems [28]. This raises the question of 


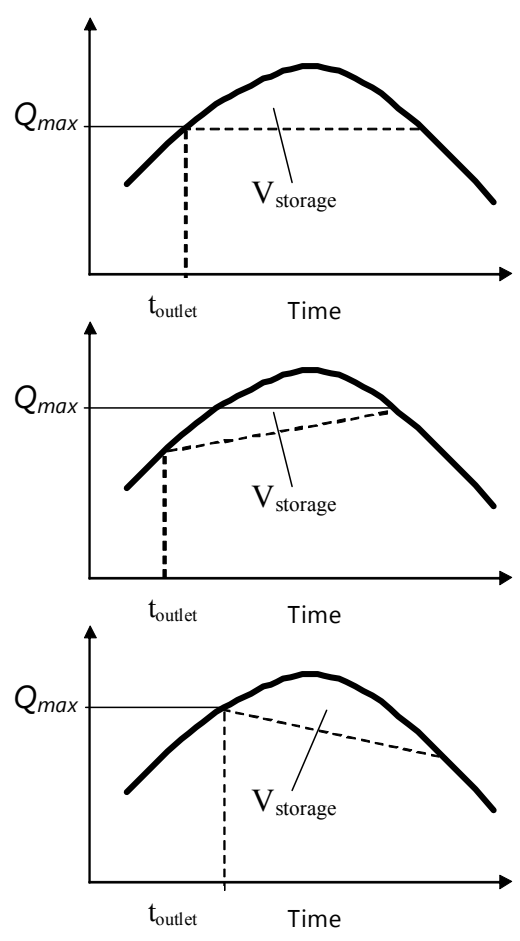

Fig. 1. Difference in timing for proper and improper timing of effectuating an emergency inundation area. $Q_{\max }$ is the maximum flow to which the flow in the river is reduced for this particular peak, shape, duration and timing, $V_{\text {storage }}$ is the volume that can be stored in the emergency inundation area and $t_{\text {outlet }}$ is the moment in time at which the spill from the river to the area starts.

how such non-structural measures should be used and what the role of prediction systems is in this. This paper strives to give a state-of-the-art overview of research addressing these questions. Particular attention is hereby given to the contributions presented in the sessions on "Water Prediction and Control Technology", organized at the 2011 IEEE International Conference on Networking Sensing and Control, Delft, The Netherlands.

This paper is organized as follows. Section II gives a state-of-the-art review on methods in forecasting and related techniques such as data assimilation and uncertainty analysis. In Section III the status of predictive control of water resources system is summarized. Section IV reflects on the combination of both disciplines. Current research in progress and directions for future research are given in Section V.

\section{Predictions In WATER SYSTEMS}

Operational predictions in water systems are traditionally applied in the context of flood forecasting [2,16]. Mainly driven by the progress in this field, the techniques became also popular for general flow forecasting [31] or even water quality applications [17]. We follow this path in our discussion before highlighting more general, supporting techniques such as data assimilation and uncertainty analysis, as well as the evolution of technical systems.

Flood events across Europe, including the 1993 and 1995 events in the Rhine and Meuse basins, the summer floods of 1997, 2002, and 2010 in the Oder, Elbe, and Danube basins, the UK floods of 2000/2001, and widespread flooding in the summer of 2005 in Southern Germany, Switzerland, Hungary, Romania, and Bulgaria frequently raise the public interest in flood protection. Besides classical structural measures such as the construction of dikes, the provision of timely flood warnings has become an accepted non-structural measure to reduce losses of property and life due to large floods [1,27].

Whilst the role of flood forecasting in the flood warning process traditionally held a modest position in the chain of detection, forecasting, warning, and response [13], its potential in added effectiveness of warnings through an increase of lead time means its significance is becoming more and more relevant in state-of-the-art systems. This lead time can be effectively used to implement measures either to reduce the consequence of flooding through for example evacuation, or to reduce flooding itself through controlling dedicated hydraulic structures [9,29,31] or adhoc interventions, such as placing sandbags.

Flow forecasting in general may serve various needs. Applications are therefore diverse and range from low water monitoring or water allocation purposes during droughts to day-to-day flow forecasting for navigation or hydropower needs. Whereas the type of hydrological model may change significantly in these applications, the technological system set-up is comparable to those of flood forecasting systems.

Water quality forecasting is a relative new discipline. Current applications aim for example at the prediction of water temperature [12]. It becomes, apart from ecological reasons, relevant to cooling water requirements of thermal power plants and therefore also affects the trading policy of energy companies. Furthermore, the forecasting of salt concentration in estuaries has been part of some coastal forecasting systems [23] when salt intrusion endangers freshwater environments. Even more complex water quality processes are covered in new forecasting systems, see the examples of [23] on the monitoring and forecasting of algae bloom and eutrophication events.

A discussion on the modeling techniques itself would go beyond the scope of this paper. However, we would like to address general techniques which typically come along with models in operational applications. The most important ones are aiming at data assimilation [2,16,17,29] and uncertainty analysis. These techniques try to update the inputs, parameters, states, or outputs of a model based on historical observations for improving the lead time accuracy of the model or for providing information of the probable model error. Whereas historical applications directly build into the models [19], state-of-the-art implementations such as OpenDA, formerly COSTA [33] and DATools [35], decouple the assimilation technique from the model itself. Uncertainty analysis tools have become popular in combination with ensemble forecasts. We refer to the international HEPEX initiative for a state-of-the-art overview in flow forecasting [32].

From a technical point of view, most forecasting systems 
in the past have been developed as an interface around a hydrological or hydraulic model, thus concentrating on the model rather than the data process [1]. Increasing availability of observed data through online telemetry and from technologies such as weather radar and quantitative precipitation forecasting are, however, requiring attention to shift to the complete process of information and data in forecasting. This has led to the development of software packages such as Delft-FEWS [36] with an open systems approach for integration of arbitrary data and models in the forecasting process. The modular approach has the advantage that many of the components used, such as the underlying models can be easily adapted or exchanged, without the need to change how the forecasting system is operated by its users. This allows for a much more rapid adaptation to advances in modeling techniques, without the added effort in organizational change.

One of the technical efforts that needs to be made in order to improve the predictions of water systems that are influenced by human interactions (operators) or automatic control loops, is to somehow include the control dynamics of these entities. Here, the knowledge of control theory can play a role that is until now in many prediction systems somewhat underexposed.

\section{CONTROL OF WATER SYSTEMS}

Non-structural measures in water systems, such as adjustable structures like gates, pumps, and sluices, are operated in order to keep water levels [9,11,29,31], flows $[5,14,24,31]$, or water quality variables $[1,17,18]$ in a desired state. There are many ways in which these adjustable structures can be controlled. Several successful implementations of control systems on water systems are described in [21]. In increasing order of information usage, three possible types of control for water systems are feedback control $[5,11,18]$, feed-forward control [17,31], and model predictive control [1,8,9,14,24,29].

To achieve a simple feedback controller, at least a measurement of the current situation, i.e., a defined system state, is necessary for a controller that determines the required actions for a non-structural measure. Feed-forward control requires that also measurements or estimates of the disturbance that is bringing the actual system state away from the desired state are known. A combination of feed-forward and feedback control is achieved using so-called model predictive control $[4,7,26]$. The control approach model predictive control can, in addition, take into account constraints when calculating the required actions. This is especially useful for control of water systems, as many constraints are present, e.g., in the form of limits on water variables and adjustable structures, and due to imposed water management regulations. Another feature of MPC is that, through optimization, conflicting subobjectives can be satisfied as much as possible.

Consider as example control of pumps in a storage canal system. The pumps in this canal system together have a maximum capacity of $60 \mathrm{~m}^{3} / \mathrm{s}$. The disturbance inflow due to runoff from an extreme storm event is higher than this
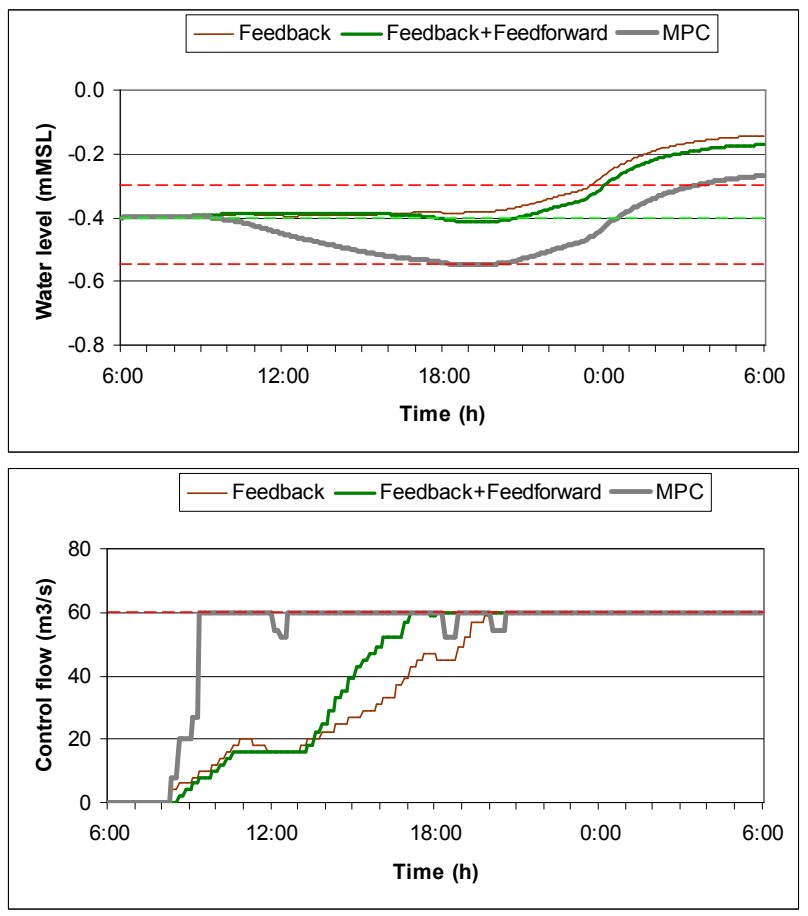

Fig. 2. Difference in control methodologies for a water system with constraints on pump outflow and water level.

capacity plus the storage capacity between set-point and the maximum allowed water level. Hence, adequate control is required. Considered is feedback, combined feedback and feedforward, and model predictive control for such a system.

A feedback controller for this system only reacts when the disturbance causes the water level to rise. As this controller only reacts after a deviation occurs, its reaction is always late. Once the control flow becomes larger than the maximum capacity of the pumps, the outflow is limited and eventually, the water level rises much higher than the maximum allowed water level, as is also seen in Figure 2.

A feedforward controller with which the feedback controller can be extended uses the prediction of the effect that the disturbance has on the water level and counteracts on this in order to keep the water level as close as possible to set-point. This works well as long as the control flow does not exceed the maximum pump capacity. Also with this control method, the maximum allowed water level constraint is violated, as is also seen in Figure 2.

A model predictive controller can use the same prediction of the disturbance as the feed-forward controller. In addition, it uses an objective function in which the water level deviation from set-point is penalized over a prediction horizon. The controller also explicitly takes into account the constrained control flow, so it can predict the high water levels at the end of the prediction horizon. To minimize the water level deviations over the entire prediction horizon, the model predictive controller starts earlier (i.e., it anticipates) with pumping out water to lower the water level before the disturbance inflow even takes place. In this way, the 
maximum allowed water level is violated to a much lower extent, as Figure 2 illustrates.

From this, we can observe that by using predictions of the upcoming event, the model predictive controller is capable of much better satisfying the objectives, while not significantly violating the operational constraints.

In addition to anticipating on predicted disturbances, there is another axes along which gains in improved water management can be achieved: coordination among several water systems. Problems never occur at the same location with the same intensity. One part of a water system can be flooded, while another part still has significant storage available. If these parts are linked and the flow is controllable, the potential flood problems can be diverted in order to lead to the lowest overall damage. This promotes the idea of not only controlling relatively small-scale water systems, but also for coordinating the non-structural measures in large-scale water systems (entire catchments). Issues with optimization for large-scale water systems can then be addressed with the emerging technology of distributed or coordinated model predictive control $[25,1]$.

It is important to note that due to the limitations on calculation time, the optimizations in model predictive control schemes can only be applied using reduced models, such as a simple (delayed) reservoir models [5,8,9,14,24]. In $[3,15,26,30,29]$, model predictive control utilizing more accurate, hydraulic models ranging from kinematic wave models to full Saint-Venant based models are implemented. These non-linear models are still significantly reduced by using a large spatial discretization. In $[38,1,17]$, the water quantity model is combined with a water quality model. It is clear, however, that ideally the most advanced prediction tools discussed in Section II would be used for providing the predictions.

\section{COMBINING PREDICTION AND CONTROL}

As the prediction tools need to be run in real-time using controller and operation modeling and as controllers are becoming more powerful when using advanced predictions, the disciplines of water systems prediction and water systems control are approaching one another. It therefore seems obvious to start combining the technologies and tools from both fields. Prediction models can benefit from knowledge of tuning fast controllers (feedback and feed-forward) that can represent the operation of the non-structural measures over the prediction horizon. Predictive control can benefit from the accurate predictions of future disturbances and input constraints, the most probable behavior of the water system when no anticipation is implemented, and the accurate evaluation of the water system's behavior resulting from the optimal control actions.

We see two implementation approaches in which prediction tools can be used in control schemes in a rather straightforward way. The first approach uses, in each iteration, two separate modules, one for generating control actions over the prediction horizon and the other for actually evaluating the consequences of these control actions using the prediction model. This is the most straightforward approach, but it also requires a large number of expensive evaluations of the high resolution, detailed prediction model. So, presently, the nonlinear prediction models need to be reduced considerably in order to be tractable $[30,8,9]$. The second approach uses the prediction model to generate time-variant bounds of the control inputs (inequality constraints) and the trajectory along which the non-linear model is linearized and reduced. Next, an efficient linear model predictive controller is formulated using this simplified model. Usually, due to the nonlinearities in the system dynamics, the steps of generating the bounds, linearizing, and solving the simply optimization problem have to be iterated a number of times before the final solution is found [4].

\section{CONCLUDING REMARKS}

In this paper, we reason that over the next decades we expect water prediction and control technologies to become accepted and powerful approaches for determining nonstructural measures that should be implemented next to structural measures. We promote the idea of optimal control of large scale water systems and the construction of adjustable structures in these water systems to increase the flexibility required for control.

Future work lies in bridging the gap between prediction and control technologies. To improve control, further improvements of predictions are necessary both in accuracy and suitability for optimization-based control. To improve predictions, it is necessary to investigate in more detail the modeling of present human-induced decision making and the way in which advanced automatic controllers can be represented in prediction tools.

\section{REFERENCES}

[1] Abhay A., Yao G. M. J., Sithanandam S., Lakshminarayanan S. (2011), "Coordinating Multiple Model Predictive Controllers for Multi-Reservoir Management", in Proceedings of the 2011 IEEE International Conference on Networking, Sensing and Control, Delft, The Netherlands.

[2] Aguilar, J.V., Langarita, P., Linares, L., Gómez, M., Rodellar, J. (2011), "An adaptive predictive approach for river level forecasting", in Proceedings of the 2011 IEEE International Conference on Networking, Sensing and Control, Delft, The Netherlands.

[3] Arnold, E., Linke, H., Puta, H. (1999), "Non-linear model predictive control for operational management of a canal system", in Proceedings of the European Control Conference 1999, Karlsruhe, Germany.

[4] Barjas Blanco, T., Willems, P., Chiang, P.-K., Cauwenberghs, K., De Moor, B., Berlamont, J. (2009), "Flood regulation by means of model predictive control", in Intelligent Infrastructures (R.R. Negenborn, Z. Lukszo, J. Hellendoorn, eds.), Springer, Dordrecht, The Netherlands, pp. 407-437.

[5] Bedjaoui, N., Weyer, E. (2011), "Control performance assessment for open water channels", in Proceedings of the 2011 IEEE International Conference on Networking, Sensing and Control, Delft, The Netherlands.

[6] Bürgi, T. (2002), "Operational flood forecasting in mountainous areasan interdisciplinary challenge", in Proceedings of the International Conference in Flood Estimation, Bern, Switzerland, pp. 397-406.

[7] Camacho, E.F., Bordons, C. (1999), "Model Predictive Control", Springer, New York.

[8] Castelletti, A., Pianosi, F., Restelli, M. (2011), "Multi-Objective Fitted Q-Iteration: Pareto frontier approximation in one single run", in Proceedings of the 2011 IEEE International Conference on Networking, Sensing and Control, Delft, The Netherlands. 
[9] Ekeren, H. van, Negenborn, R.R., Overloop, P.J. van, De Schutter, B. (2011), "Hybrid model predictive control using time-instant optimization for the Rhine-Meuse Delta", in Proceedings of the 2011 IEEE International Conference on Networking, Sensing and Control, Delft, The Netherlands.

[10] Grijsen, J., Snoeker, X., Vermeulen, C., El Amin Moh. Nur, M., Mohamed, Y.A. (1992), "An information system for flood early warning", in Proceedings of the 3rd International Conference on Floods and Flood Management, Florence, Italy, pp. 263-289.

[11] Guan, G. Wang, C., Clemmens, A.J. (2011), "Optimizing Indicator Choosing for Canal Control System and Simulation Study", in Proceedings of the 2011 IEEE International Conference on Networking, Sensing and Control, Delft, The Netherlands.

[12] Haag, I., Luce, A. (2008), "LARSIM-WT: An integrated waterbalance and heat-balance model to simulate and predict stream water temperatures", Hydrological Processes, vol. 22, pp. 1046-1056.

[13] Haggett, C. (1998), "An integrated approach to Flood Forecasting and Warning in England and Wales", Journal of the Chartered Institution of Water and Environmental Management, vol. 12, pp. 425-432.

[14] Kearney, M., Cantoni, M., Dower, P. M. (2011), "Model predictive control for systems with scheduled load and its application to automated irrigation channels", in Proceedings of the 2011 IEEE International Conference on Networking, Sensing and Control, Delft, The Netherlands.

[15] Linke, A, (2010), "A model-predictive controller for optimal hydropower utilization of river reservoirs", in Proceedings of the IEEE Multiconference on Systems and Control, Yokohama, Japan.

[16] Linke, H., Karimanzira, D., Rauschenbach, T., Pfützenreuter, T. (2011), "Flash flood prediction for small rivers", in Proceedings of the 2011 IEEE International Conference on Networking, Sensing and Control, Delft, The Netherlands.

[17] Litrico, X., Belaud, G., Fovet, O. (2011), "Adaptive control of algae detachment in regulated canal networks", in Proceedings of the 2011 IEEE International Conference on Networking, Sensing and Control, Delft, The Netherlands.

[18] Liu, G., Wang, C., Guan, G. (2011), "Study on Transition Mode of the Middle Route of South-to-North Water Transfer Project before Freezing", in Proceedings of the 2011 IEEE International Conference on Networking, Sensing and Control, Delft, The Netherlands.

[19] Ludwig, K., Bremicker, M. (Eds.) (2006), "The Water Balance Model LARSIM", Freiburger Schriften zur Hydrologie, Band 22 Institüt für Hydrologie der Universität Freiburg.

[20] Madsen, H., Butts, M., Khu, S., Liong, S. (2000), "Data assimilation in rainfall runoff forecasting", in Proceedings of the 4th Hydroinformatics Conference, Cedar Rapids, Iowa.

[21] Malaterre, P.O., Rogers, D.C., Schuurmans, J. (1998b), "Classification of canal control algorithms", Journal of Irrigation and Drainage Engineering, vol. 124, pp. 3-10.

[22] Moore, R., Jones, D. (1998), "Linking hydrological and hydrodynamic forecast models and their data", in Proceedings of the first RIBAMOD workshop: "River Basin Modeling, management and flood mitigation", European Community, EUR18019EN, pp. 37-56.

[23] Nauta, T., Chang, C.W., Smits, J., Lee, E., Brinkman, J, (2008). "Operational Management System for Marina Reservoir, Singapore", in Proceedings of the 1st Singapore International Water Week.

[24] Nederkoorn, E., Schuurmans, J., Schuurman, W. (2011), "Continuous Nonlinear Model Predictive Control of a Hybrid Water System Application of DNPC to a Dutch Polder", in Proceedings of the 2011 IEEE International Conference on Networking, Sensing and Control, Delft, The Netherlands.

[25] Negenborn, R.R., Overloop, P.J. van, Keviczky, T., De Schutter, B. (2009), "Distributed model predictive control for irrigation canals", Networks and Heterogeneous Media, vol. 4, pp. 359-380.

[26] Overloop, P.J. van, (2006), "Model Predictive Control on Open Water Systems", PhD thesis, Delft University of Technology, The Netherlands.

[27] Roo, A. de, Gouweleeuw, B., Thielen, J., Bartholmes, J., Bongioannini-Cerlini, P., Todini, E., Bates, P., Horritt, M., Hunter, N., Beven, K., Pappenberger, F., Heise, E., Rivin, G., Hills, M., Hollingsworth, A., Holst, B., Kwadijk, J., Reggiani, P., van Dijk, M., Sattler, K., and Sprokkereef, E. (2003), "Development of a European Flood Forecasting System", International Journal on River Basin Management, vol. 1, pp. 49-59.

[28] Schielen, R., Jesse, P., Bolwidt, L. (2006), "On the use of flexible spilllways to control the discharge distribution of the Rhine in the
Netherlands: hydraulic and morphological observations", Netherlands Journal of Geosciences-Geologie en Mijnbouw, vol. 86, pp. 319-330.

29] Schwanenberg, D., Hummel, S. (2011), "Data Assimilation for Supporting Optimum Control in Large-Scale River Networks", in Proceedings of the 2011 IEEE International Conference on Networking, Sensing and Control, Delft, The Netherlands.

[30] Schwanenberg, D., Verhoeven, G.F., Boogaard, H. van den, Overloop, P.J. van (2010), "Non-linear model predictive control of flood detentions basins in operational flood forecasting", in Proceedings of the 9th International Conference on Hydroinformatics, Tianjin, China.

[31] Theobald, U., Theobald, S. (2011), "Central Water Resources Management in a cascade of hydropower plants", in Proceedings of the 2011 IEEE International Conference on Networking, Sensing and Control, Delft, The Netherlands.

[32] Thielen, J., Schaake, J. (Eds.) (2009). "Special Issue: HEPEX Workshop: Stresa, Italy, June 2007”, Atmospheric Science Letters, vol. 9.

[33] Velzen, N. van, Verlaan, M. (2007), "COSTA a problem solving environment for data assimilation applied for hydrodynamical modeling", Meteorologische Zeitschrift, vol. 16, pp. 777-793.

[34] Wahlin, B.T. (2004), "Performance of model predictive control on ASCE Test Canal 1", Journal of Irrigation and Drainagee Engineering, vol. 130, pp. 227-238.

[35] Weerts, A.H., El Serafy, G.Y., Hummel, S., Dhondia, J., Gerritsen, H. (2010), "Application of generic data assimilation tools (DATools) for flood forecasting purposes" Computers \& Geosciences, vol. 36, pp. 453-463.

[36] Werner, M., Dijk, M. van, Schellekens, J. (2004), "DELFT-FEWS: An open shell flood forecasting system", in Proceedings of the 6th International Conference on Hydroinformatics, Singapore, pp. 12051212 .

[37] Werner, M., Whitfield, D. (2007), "On model integration in operational flood forecasting" Hydrological Processes, vol. 21, pp. 1519-1521.

[38] Xu, M., Overloop, P.J. van, Giesen, N.C. van de, Stelling, G.S. (2010), "Real-time control of combined surface water quantity and quality: polder flushing", Water Science and Technology, vol. 61, pp. 869-878. 